\title{
Potassium isotopic composition of low-temperature altered oceanic crust and its impact on the global $K$ cycle
}

\author{
Haiyang Liu ${ }^{1,2,3,4 *}$, Ying-Yu Xue $e^{1,2,3}$, Guoliang \\ Zhang ${ }^{1,2,3}$, Wei-Dong Sun ${ }^{1,2,3}$, Zhen Tian ${ }^{4}$, Brenna \\ Tuller-Ross ${ }^{4}$ and Kun Wang $\left(\right.$ 王昆 ${ }^{4 *}$ \\ ${ }^{1}$ Center of Deep Sea Research, Institute of Oceanology, \\ Chinese Academy of Sciences, Qingdao 266071, P. R. \\ China (*Correspondence: hyliu@qdio.ac.cn) \\ ${ }^{2}$ Qingdao National Laboratory for Marine Science and \\ Technology, Qingdao 266237, P. R. China \\ ${ }^{3}$ Center for Ocean Mega-Science, Chinese Academy of \\ Sciences, Qingdao 266071, P. R. China \\ ${ }^{4}$ Department of Earth and Planetary Sciences, Washington \\ University in St. Louis, St. Louis, MO 63130, USA \\ (*Correspondence: wangkun@wustl.edu)
}

To constrain the behavior of $\mathrm{K}$ isotopes during lowtemperature alteration of oceanic crust and reveal its impact on the global $\mathrm{K}$ cycle, we measured $\mathrm{K}$ isotopic compositions of 49 basalts recovered at Integrated Ocean Drilling Program (IODP) Sites U1365 ( 100 Ma) and U1368 ( 13.5 Ma) in the South Pacific, with different low-temperature alteration styles and intensities. The fresh basalts from both Sites in general show similar $\mathrm{K}$ isotopic compositions to the fresh mid-ocean ridge basalts (MORB), with $\delta^{41} \mathrm{~K}$ values ranging from $0.55 \%$ to $-0.23 \%$ (average $-0.39 \pm 0.18 \%$, $2 \mathrm{sd}$ ). In contrast, the measured $\delta^{41} \mathrm{~K}$ values of the altered basalts vary within a larger range $(-0.76 \%$ to $-0.17 \%$, average $-0.44 \pm 0.33 \%$, $2 \mathrm{sd})$. Moreover, a positive correlation between $\delta^{41} \mathrm{~K}$ values and $\mathrm{K}_{2} \mathrm{O}$ contents (also $\mathrm{K} / \mathrm{Nb}$ ratios) of the altered basalts was observed in Site U1365 ( 100 Ma), which is consistent with isotopically heavy $\mathrm{K}$ from seawater being absorbed into authigenic clays during low-temperature alteration. In addition, the general correlation between $\delta^{41} \mathrm{~K}$ values and alteration intensity (i.e., degrees of $\mathrm{K}$ enrichment) rather than with the alteration type (i.e., dominant alteration minerals) indicates that the scale of $\mathrm{K}$ isotope fractionation is largely controlled by the alteration intensity. Collectively, a weighted average $\delta^{41} \mathrm{~K}$ value of $-0.40 \pm 0.33 \%$, (2sd) is given for the low-temperature altered oceanic crust (AOC) at Sites U1365 and U1368, which is indistinguishable from the MORB value. However, the heterogeneous $\mathrm{K}$ isotopic compositions of the low-temperature AOC, together with large fractionation scale during the subsequent subduction dehydration, further highlights the utility of $\mathrm{K}$ isotope systems to trace subducted crustal materials. 